\title{
Analysis of the Risk Factors for Allograft Vasculopathy in Asymptomatic Patients after Cardiac Transplantation
}

\author{
Fernando Bacal, Viviane Cordeiro Veiga, Alfredo Inácio Fiorelli, Giovanni Bellotti, Edimar Alcides Bocchi, \\ Noedir Antonio Groppo Stolf, José Antonio Franchini Ramires
}

São Paulo, SP - Brazil

\begin{abstract}
Objective - To study the influence of immune and nonimmune risk factors on the development of allograft vasculopathy after cardiac transplantation.
\end{abstract}

Methods - We studied 39 patients with a mean age of $46 \pm 12$ years. The following variables were analyzed: weight $(\mathrm{kg})$, body mass index $\left(\mathrm{kg} / \mathrm{m}^{2}\right)$, donor's age and sex, rejection episodes in the first and second years after transplantation, systolic and diastolic blood pressures $(\mathrm{mmHg})$, total cholesterol and fractions $(\mathrm{mg} / \mathrm{dL})$, triglycerides $(\mathrm{mg} /$ $d L)$, diabetes, and cytomegalovirus infection. The presence of allograft vasculopathy was established through coronary angiography.

Results - Allograft vasculopathy was observed in 15 (38\%) patients. No statistically significant difference was observed between the two groups in regard to hypertension, cytomegalovirus infection, diabetes, donor's sex and age, rejection episodes in the first and second years after transplantation, and cholesterol levels. We observed a tendency toward higher levels of triglycerides in the group with disease. Univariate and multivariate analyses showed statistically significant differences between the two groups when we analyzed the body mass index $(24.53 \pm 4.3$ versus 28.11 \pm 4.6 ; $p=0.019$ ).

Conclusion - Body mass index was an important marker of allograft vasculopathy in the population studied.

Key words: cardiac transplantation, allograft vasculopathy, risk factors, body mass index

Instituto do Coração do Hospital das Clínicas - FMUSP

Mailing address: Fernando Bacal - InCor - Av. Dr. Enéas C. Aguiar, 44 - $05403-$ 000 - São Paulo, SP, Brazil

English Version by Stela Maris C. Gandour
Allograft vasculopathy has remained the most important late complication in the follow-up of patients undergoing cardiac transplantation, despite the great advances obtained in controlling rejection and infection episodes, with a consequent reduction in total mortality. Interest in understanding and controlling allograft vasculopathy had already been evident since the beginning of transplantation programs, even in the experimental phase of technique development.

Lower et al ${ }^{1}$ were the first to report the appearance of coronary atherosclerosis in a dog undergoing cardiac transplantation, showing that this complication could affect the late posttransplantation evolution. In 1969, however, Thompson et al ${ }^{2}$ first reported coronary artery disease affecting human grafts one year after the first experimental report.

The term allograft vasculopathy has been adopted to represent the disease instead of posttransplantation accelerated coronary artery disease or atherosclerosis, because this disease is also found in renal, hepatic, and lung transplantations, contributing to the functional deterioration of the respective organs in late follow-up. This is the major cause of indication for retransplantations ${ }^{3}$. Allograft vasculopathy has remained the major cause of death in late posttransplantation follow-up, and its incidence has reached levels of approximately $10 \%$ per year of the postoperative period, reaching $40 \%$ to $50 \%$ in recipients who have completed the fifth year of follow-up.

In a series of patients operated upon at the Instituto do Coração of FMUSP, Fiorelli et al ${ }^{4}$ found an incidence of $44 \%$ of allograft vasculopathy by the end of the fifth year of clinical follow-up after surgery. These data resemble those reported by other groups ${ }^{5-10}$. Even though not completely clarified, we believe that allograft vasculopathy results from an immunologically mediated phenomenon aggravated by atherogenic involvement. When the histologic characteristics of the coronary artery lesion are analyzed, we observe a predominance of macrophages and cytotoxic T lymphocytes, proliferation of smooth muscle cells, and myointimal hyperplasia, resulting in concentric luminal stenosis, which is also found in early restenosis following angioplasty ${ }^{11,12}$. 
Some immune and nonimmune risk factors seem to contribute to the development of the disease; this issue, however, remains controversial. The immune risk factors involved are HLA histocompatibility, rejection episodes, and donor's sex. The nonimmune factors are duration of ischemia, diagnosis of pretransplantation ischemic heart disease, cytomegalovirus infection, systemic hypertension, dyslipidemia, obesity, diabetes, sedentary lifestyle, smoking, and the immunosuppression regimen used.

The endothelial lesion associated with cofactors, such as cytokines and growth factors, could predispose a patient to proliferation of smooth muscle cells and macrophages, which are typical changes of allograft vasculopathy. Understanding the pathophysiological mechanism of the disease has motivated several groups to discover therapeutical alternatives in the attempt to reduce the complications resulting from this disease.

The objective of this study was to assess the influence of immune and nonimmune risk factors in the development of allograft vasculopathy in patients undergoing cardiac transplantation in our institution.

\section{Methods}

We studied 39 patients who had undergone orthotopic cardiac transplantation at the Instituto do Coração of the Hospital das Clínicas of FMUSP. Their mean age was 46 \pm 12 years, and the mean follow-up time was $86 \pm 31$ months.

We chose the patients with a postoperative follow-up period longer than 2 years, who were clinically stable, asymptomatic, and who agreed to undergo the study protocol, according to the Ethics Committee of the Hospital das Clínicas of FMUSP, through the signature of a formal consent form by the patient or guardian.

On periodical out patient medical visits, the patients without symptoms of angina or heart failure underwent echocardiography for assessing ventricular function. The patients with normal ventricular function and no segmentary hypocontractility were included in the study. The patients also underwent endomyocardial biopsy of the right ventricle when they had not undergone scintigraphy with gallium-67 in the last month, to exclude the diagnosis of acute rejection that could interfere with data analysis. The medications used for controlling postoperative arterial hypertension and dyslipidemia were maintained during the period of examination.

Clinical and laboratory data collection was carried out in a single week of the study. These data were correlated with information obtained from coronary angiography to analyze the influence of risk factors in the development of allograft vasculopathy.

The exclusion criteria were as follows: postoperative evolution shorter than 2 years, anginal or heart failure symptoms, global or segmentary ventricular dysfunction evident on echocardiography at rest, acute rejection $\leq 3 \mathrm{~A}$, incomplete adherence to the protocol.

Variables studied - We considered the results obtained in the week of study, and occasional variations between the preoperative and postoperative values were not considered. The variables studied were the following: 1 ) laboratory assessment: total cholesterol (mg/dL), HDL (mg/ $\mathrm{dL}$ ), LDL (mg/dL), triglycerides (mg/dL); 2) constitutional characteristics of the recipients: age (years), weight $(\mathrm{kg})$, height (m), and body mass index (BMI). The BMI was calculated according to the formula: $\mathrm{BMI}=$ weight $(\mathrm{kg}) / \mathrm{height}^{2}$ $\left(\mathrm{m}^{2}\right)$ and the values were analyzed as follows: BMI $<18.5$, diagnosis: malnutrition; $\mathrm{BMI}>18.5$, diagnosis: eutrophia; BMI > 25.0, diagnosis: overweight or obesity; $\mathrm{BMI}>30.0$, diagnosis: grade II obesity; BMI >40.0, diagnosis: grade III obesity; 3) postoperative time (months); 4) systolic and diastolic blood pressure ( $\mathrm{mmHg}$ ) - we considered the measurements obtained on an out patient basis during the week of data collection; 5) number of rejection episodes during the first and second postoperative years - this was a retrospective analysis. We studied the endomyocardial biopsy of patients undergoing cardiac transplantation available at the Incor-HCFMUSP department of pathology. Rejection episodes $\leq 3 \mathrm{~A}$ were considered relevant, according to the criteria of the International Society of Heart-Lung Transplantation (ISHLT) ${ }^{13}$; 6) donor's age and sex; 7) we considered as cytomegalovirus infection those cases with suggestive clinical findings, such as fever, leukopenia, hepatitis or pneumonia, or both, confirmed by serologic examination or antigenemia higher than 10 cells, but we did not consider those cases of infection in which serology was positive (IgG+) but no clinical manifestation was found.

Coronary angiography - We adopted the technique of Sones et al ${ }^{14}$. We used the Phillips device, Optimus 1050 model, with an image intensifier from 6.5 to 9 inches coupled with an Arritecno recording camera, with 30 frames per second. The films were separately analyzed by two specialists from the hemodynamics service at Incor, who did not have previous knowledge of the clinical and laboratory data of the patients. We analyzed each artery to establish the degree of luminal reduction in at least two views: right anterior oblique and left anterior oblique views. This method was considered the gold standard for definition of the presence or absence of allograft vasculopathy. The test was considered positive for allograft vasculopathy when luminal obstruction was $\geq 50 \%{ }^{15-17}$, and we used the designations: disease YES or NO. Lesions < $50 \%$ were considered as parietal irregularities and were not evaluated.

Statistical analysis - At first we analyzed all 39 patients and summarized the quantitative data by the minimum and maximum values, median, mean, and standard deviation, and the qualitative data by the tables of absolute and relative frequencies.

We studied the possible predictive factors for the development of coronary artery disease, initially with univariate analysis, and then with multivariate analysis, where Pearson's chi-square test and Fisher exact test were used to compare those patients developing and those not developing coronary artery disease in regard to the homogeneity of proportions. Fisher exact test was used in contingency tables with expected values $<5$. 
The Student's $t$ test and the Wilcoxon test were used to compare the quantitative data between the patients developing the disease and those not developing the disease. With the first method, the means were compared; however, when the necessary suppositions for the use of the Student's $t$ test were not met, we used the Wilcoxon test, where the medians were compared.

To estimate the probability of developing coronary artery disease based on the variables selected in the univariate analysis, through a multivariate model, we used the logistic regression technique ${ }^{18}$. To select the most important variables, we used the procedure of selecting stepwise variables, assuming a significance level of 0.1 or $10 \%$ in the univariate analysis.

We established a significance level of $5 \%$ for analysis, and the entire calculation was performed with the SAS (Statistical Analysis System) ${ }^{19}$.

\section{Results}

Of the 39 patients studied, 15 (38.4\%) had allograft vasculopathy on coronary angiography, characterized by an obstructive coronary lesion $=50 \%$ in at least one vessel. We studied 15 patients in the period from the $2^{\text {nd }}$ to the $5^{\text {th }}$ postoperative years, 17 patients from the $6^{\text {th }}$ to the $9^{\text {th }}$ postoperative years, and 7 patients from the $10^{\text {th }}$ postoperative year onwards.

Table I shows the statistical data regarding age, height, weight, and body mass index. The group with disease had a tendency toward greater weight but with no statisti- cal significance $(68.83 \pm 13.54 \mathrm{~kg}$ versus $78.53 \pm 19.17 \mathrm{~kg}$; $\mathrm{p}=0.072$ ).

Body mass index was an independent risk factor for developing allograft vasculopathy, and the patients with disease showed higher values than the patients in the other group $\left(28.11 \pm 4.60 \mathrm{~kg} / \mathrm{m}^{2}\right.$ versus $\left.24.53 \pm 4.36 \mathrm{~kg} / \mathrm{m}^{2} ; \mathrm{p}=0.019\right)$.

Other variables, such as donor's age and number of rejection episodes during the first and second postoperative years showed no statistically significant differences between the two groups (Table II). In regard to time of transplantation, the values obtained were $79.21 \pm 31.18$ months for the group without disease versus $97.33 \pm 29.41$ months for the group with disease $(\mathrm{p}=0.793)$.

We observed a tendency toward higher levels of triglycerides in the group with allograft vasculopathy as compared with the patients with normal coronary angiography $(p=0.097)$. The values of systolic and diastolic blood pressures, total cholesterol, HDL, and LDL are shown in table III, and no statistically significant differences were observed.

When we analyzed the cause of pretransplantation basic cardiomyopathy in regard to the occurrence of allograft vasculopathy in individuals undergoing cardiac transplantation, we observed a predominance of patients with idiopathic dilated cardiomyopathy (8 patients), followed by ischemic patients (4), chagasic patients (2), and rheumatic patient (1). The prevalence of the disease was lower in chagasic patients; when comparing, however, the chagasic group with the nonchagasic group in regard to development of allograft vasculopathy, we found no statistical significance $(\mathrm{p}=0.150)$. The presence of diabetes, the influence

\begin{tabular}{|c|c|c|c|c|c|c|c|c|}
\hline Variable & Disease & $\mathrm{N}^{\circ}$ & Minimum & Maximum & Median & Mean & SD & $P$ \\
\hline \multirow[t]{2}{*}{ Age (anos) } & No & 24 & 18.00 & 69.00 & 45.50 & 44.96 & 12.87 & 0.432 \\
\hline & Yes & 15 & 13.00 & 65.00 & 52.00 & 48.40 & 13.62 & \\
\hline \multirow[t]{2}{*}{ Height (m) } & No & 24 & 1.45 & 1.79 & 1.68 & 1.67 & 0.09 & 0.640 \\
\hline & Yes & 15 & 1.42 & 1.78 & 1.68 & 1.66 & 0.10 & \\
\hline \multirow[t]{2}{*}{ Weight (kg) } & No & 24 & 47.00 & 99.00 & 69.00 & 68.83 & 13.54 & 0.072 \\
\hline & Yes & 15 & 42.00 & 115.00 & 80.00 & 78.53 & 19.17 & \\
\hline \multirow[t]{2}{*}{$\operatorname{BMI}\left(\mathrm{kg} / \mathrm{m}^{2}\right)$} & No & 24 & 18.04 & 37.46 & 24.28 & 24.53 & 4.36 & 0.019 \\
\hline & Yes & 15 & 20.83 & 37.55 & 28.72 & 28.11 & 4.60 & \\
\hline
\end{tabular}

\begin{tabular}{|c|c|c|c|c|c|c|c|c|}
\hline Variable & Disease & $\mathrm{N}^{\circ}$ & Minimum & Maximum & Median & Mean & SD & $P$ \\
\hline \multirow{2}{*}{$\begin{array}{l}\text { Donor's age } \\
\text { (years) }\end{array}$} & No & 24 & 16.00 & 42.00 & 26.50 & 27.00 & 8.08 & 0.572 \\
\hline & Yes & 15 & 14.00 & 40.00 & 31.00 & 28.53 & 8.33 & \\
\hline \multirow[t]{2}{*}{ Rejections ( $1^{\text {st }}$ year $)$} & No & 24 & 0.00 & 5.00 & 1.00 & 1.75 & 1.51 & 0.755 \\
\hline & Yes & 15 & 0.00 & 5.00 & 2.00 & 1.80 & 1.32 & \\
\hline \multirow[t]{2}{*}{ Rejections ( $2^{\text {nd }}$ year) } & No & 24 & 0.00 & 3.00 & 1.00 & 0.96 & 1.08 & 1.000 \\
\hline & Yes & 15 & 0.00 & 5.00 & 1.00 & 1.13 & 1.55 & \\
\hline \multirow[t]{2}{*}{ Time of TX } & No & 24 & 25.00 & 148.00 & 79.00 & 79.21 & 31.18 & 0.793 \\
\hline & Yes & 15 & 49,00 & 144.00 & 98.00 & 97.33 & 29.41 & \\
\hline
\end{tabular}


of the donor's sex, and posttransplantation cytomegalovirus infection showed no influence on the development of allograft vasculopathy in either group (Table IV).

From the variables with a statistical trend or significance in the univariate analysis, we selected the following for the multivariate analysis: weight, body mass index, and triglycerides. The body mass index was the only predictive factor for developing allograft vasculopathy.

The logistic regression graph shows the probability of developing allograft vasculopathy as the body mass index increases. At each unit increase in body mass index, the chance of developing disease increases 1.197 times. With an increase of 5 units in body mass index, the chance of developing the disease increases 2.459 times (fig. 2).

\section{Discussion}

The real role of cellular rejection in the development of allograft vasculopathy still remains controversial. Helper T lymphocytes seem to play an important role in this process, as they are activated by class II HLA antigens, which are expressed in vascular endothelial cells and smooth muscle cells. When activated, these lymphocytes may also produce interferon gamma, which stimulates the release of adhesion molecules leading to activation of macrophages, resulting in an increase in growth factors, such as interleukin-6, interleukin-1, and platelet-derived growth factors. These, when released, cause proliferation of smooth muscle cells, leading to a progressive luminal obstruction, characteristic of allograft vasculopathy. Another point not yet clarified is the influence of the number of rejection episodes and their consequent participation in the development of allograft vasculopathy. Uretsky et al ${ }^{15}$ have found a relation between allograft vasculopathy and the occurrence of two or more rejection episodes. These data were corroborated by Radovancevic et al ${ }^{20}$ when they analyzed the experience of the Texas Heart Institute; these results, however, were not confirmed by data of other study groups such as the one by Gao et al ${ }^{21}$ at Stanford University. In the present series, we have found no statistically significant difference between the group with allograft vasculopathy and the group with a normal coronary angiography in regard to the number of rejection episodes. We should stress, however, that this observation takes into consideration that the biopsy is limited, reflecting a focal situation and not often representing the myocardium as a whole. Another impor-

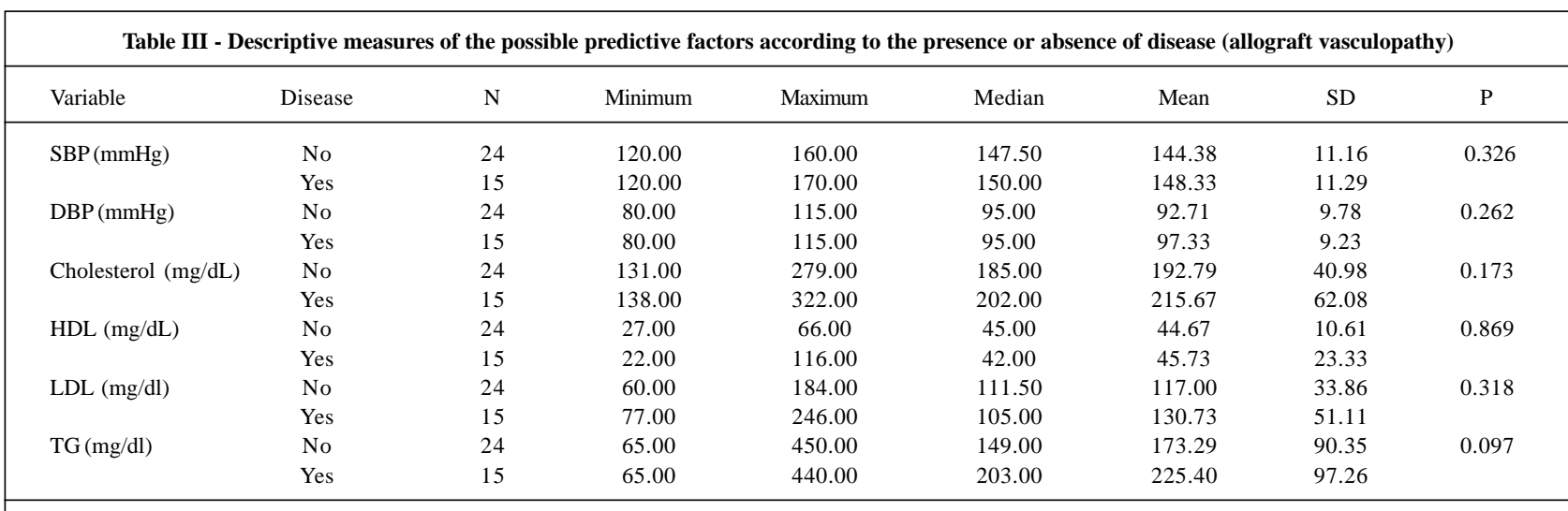

SBP - systolic blood pressure; DBP - diastolic blood pressure; HDL - HDL fraction of cholesterol; LDL - LDL fraction of cholesterol; TG - triglycerides; N number of patients; SD - standard deviation.

\begin{tabular}{|c|c|c|c|c|c|c|c|}
\hline \multirow{3}{*}{ Variable } & \multirow{3}{*}{ Category } & \multicolumn{4}{|c|}{ Disease } & \multirow{3}{*}{ Total } & \multirow{3}{*}{$\mathrm{P}$} \\
\hline & & & & & & & \\
\hline & & $\mathrm{N}$ & $\%$ & $\mathrm{~N}$ & $\%$ & & \\
\hline \multirow{4}{*}{ Etiology } & Chagas & 9 & 81,82 & 2 & 18,18 & 11 & 0,327 \\
\hline & Dilated & 11 & 57,89 & 8 & 42,11 & 19 & \\
\hline & Ischemic & 3 & 42,86 & 4 & 57,14 & 7 & \\
\hline & Rheumatic & 1 & 50,00 & 1 & 50,00 & 2 & \\
\hline \multirow[t]{2}{*}{ Diabetes } & No & 18 & 62,07 & 11 & 37,93 & 29 & 1,000 \\
\hline & Yes & 6 & 60,00 & 4 & 40,00 & 10 & \\
\hline \multirow[t]{2}{*}{ Donor's sex } & Female & 3 & 75,00 & 1 & 25,00 & 4 & 1,000 \\
\hline & Male & 21 & 60,00 & 14 & 40,00 & 35 & \\
\hline \multirow[t]{2}{*}{ CMV infection } & No & 20 & 57,14 & 15 & 42,86 & 35 & 0,146 \\
\hline & Yes & 4 & 100,00 & 0 & 0,00 & 4 & \\
\hline
\end{tabular}




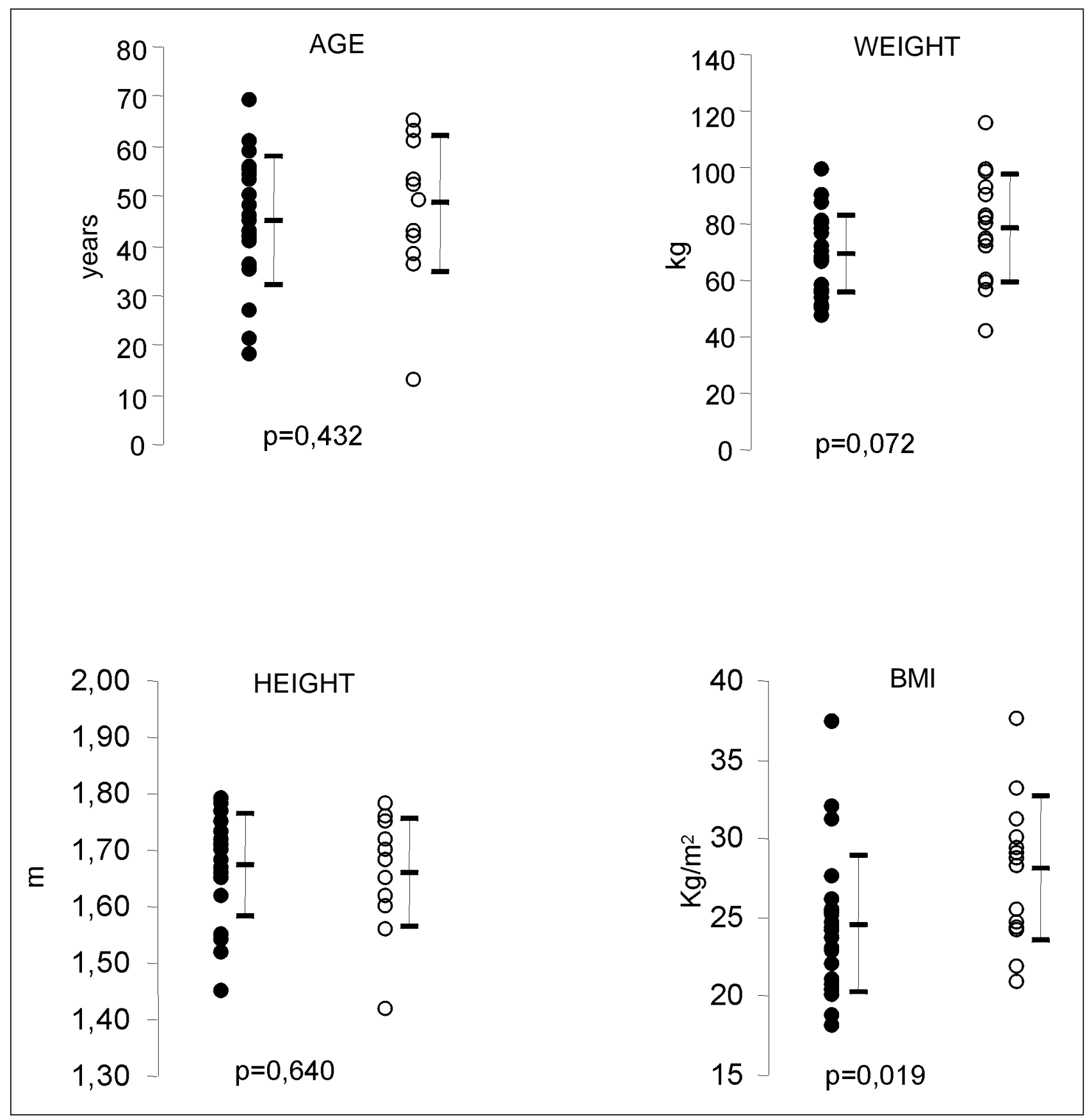

Fig. 1 - Mean values of the constitutional characteristics of the patients. $\bullet$ no allograft vasculopathy; $\bigcirc$ allograft vasculopathy; BMI - body mass index.

tant point is that the assessment of rejection episodes in stable out patients was performed with scintigraphy with gallium-67 and, occasionally, one episode of moderate rejection may not have been diagnosed because of limitations of the method. Humoral rejection also seems to play a role in the development of allograft vasculopathy through endothelial lesion. This concept is based on the presence of cytotoxic antibodies directed against the HLA-DR antigen of the vascular endothelium, the relation of the presence of class I and II anti-HLA cytotoxic antibodies in patients with posttransplantation allograft vasculopathy, and the detection through immunofluorescence of immunoglobulins and complement in the vascular endothelium ${ }^{22,23}$. However, it is worth stressing that this type of rejection usually manifests with hemodynamic impairment and high mortality and, when we select the clinically stable patients with normal ventricular function for study, we may not be including the real representation of this type of rejection in the analysis.

Hypertension may perhaps be the most common complication associated with the use of cyclosporine in patients undergoing cardiac transplantation, and its incidence has ranged from 50 to $100 \%$ in several series ${ }^{15,24,25}$. The mechanisms involved in this process have not been totally clarified; cyclosporine, however, is known to cause a 


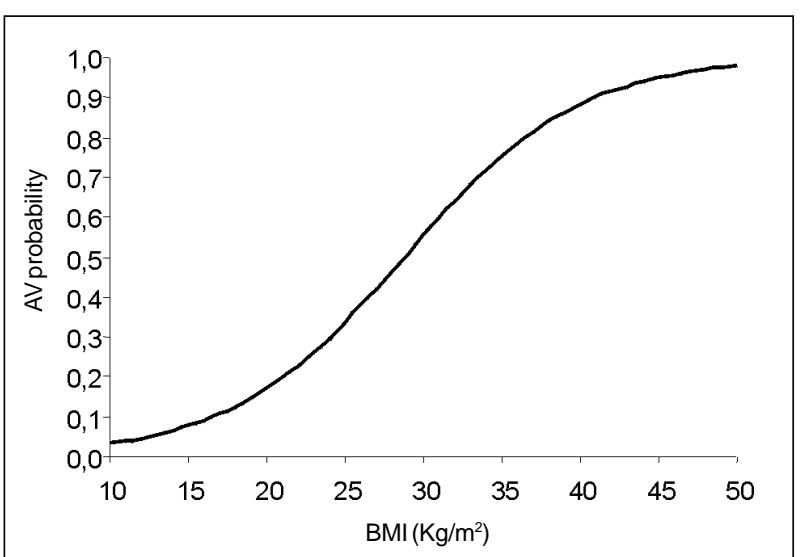

Fig. 2 - The logistic regression graph shows the relation between body mass index (BMI) and the probability to develop allograft vasculopathy (AV).

state of avidity for sodium with a consequent decrease in its fraction of excretion. The association with its renal vascular effects, such as a reduction in renal blood flow and an increase in intrarenal vascular resistance, contributes to the state of hypertension ${ }^{7}$. Posttransplantation heart denervation also seems to be involved in developing hypertension, because it causes loss of normal baroreflexes. From the practical point of view, controlling the pressure levels of patients is very difficult, despite the use of a large range of antihypertensive medications, probably because of its multifactorial character added to the direct influence of immunosuppressive medications, such as cyclosporine and prednisone. In the general population, the influence of arterial hypertension on coronary events is well known. However in the population of cardiac transplantation patients, this relation has not yet been shown, which confirms our results. It is important to stress that in our study, the pressure levels obtained in the two groups may have been influenced by the use of antihypertensive medication, as most of the patients were using this class of drug during the study.

Cytomegalovirus infection has also been studied to better understand its real role in the genesis of conventional atherosclerosis and, more specifically, of posttransplantation allograft vasculopathy ${ }^{26}$. This infectious agent, which belongs to the herpes virus group, has an incidence ranging from 30 to $100 \%$ in patients awaiting cardiac transplantation, depending mainly on cultural and social aspects of each country. In the United States, the incidence of positive sero$\operatorname{logy}$ for cytomegalovirus is 60 to $70 \%$ of the population ${ }^{27}$; in Brazil, it reaches more than $90 \%{ }^{28}$. The mechanism by which cytomegalovirus may lead to atherosclerosis has not been well established; however, it is believed to stimulate the proliferation of smooth muscle cells and to cause procoagulant changes in the endothelium, contributing to the formation of atherosclerotic plaque ${ }^{29}$. The first report on the association of cytomegalovirus and allograft vasculopathy was by Grattan et $\mathrm{al}^{30}$ at Stanford University. Later, other groups showed the same association and since then the pretransplantation use of ganciclovir has been propo- sed for prophylaxis in patients with negative serology for cytomegalovirus ${ }^{31,32}$. Clinical manifestation of cytomegalovirus infection may be found both in seronegative patients, the so-called primary infection, and seropositive patients, the so-called clinical reactivation. Reactivation is usually more benign and has a mild and self-limited fever; primary infection, however, may present as a systemic illness characterized by fever, leukopenia, gastrointestinal involvement, pneumonitis, and has high morbidity and mortality. The risk factors for severe infections by cytomegalovirus are believed to be the following: seronegative individuals who receive an organ from a seropositive donor, and patients requiring high doses of immunosuppressants for treating refractory rejections or as an inducing therapy with lymphocytolytic agents. As almost our entire population of patients is seropositive for cytomegalovirus in the pretransplantation period, we have chosen to evaluate only those with suggestive clinical findings, followed by a serologic confirmation or by antigenemia values higher than 10 cells, which happened in 4 patients. These patients were then treated with ganciclovir and had a good clinical evolution. Coronary angiography revealed that these patients did not have allograft vasculopathy, i.e., in our series we found no relation between this risk factor and the development of allograft vasculopathy. These results, however, await confirmation with studies involving a greater number of patients and comparison with a subpopulation of seronegative patients in the pretransplantation assessment.

Another very important point in the context of the risk factors for developing allograft vasculopathy is dyslipidemia. Its influence in atherosclerosis and, more precisely, in conventional coronary artery disease is well established; therefore, we currently use all resources for the appropriate control of cholesterol and triglyceride levels, mainly in patients at higher risk. In patients undergoing cardiac transplantation, dyslipidemia also seems to exert an influence on the multifactorial context, which culminates in allograft vasculopathy. The levels of LDL-cholesterol and triglycerides begin to increase in the second postoperative week and reach a peak around the $3^{\text {rd }}$ to the $6^{\text {th }}$ month. Immunosuppressants, mainly cyclosporine and corticosteroids, seem to directly contribute to posttransplantation dyslipidemia ${ }^{33-37}$. Prednisone works by increasing the hepatic production of apolipoprotein B, predisposing the patient to insulin resistance, reducing the activity of the lipoprotein lipase, and decisively contributing to the weight gain observed in patients in the postoperative period ${ }^{38}$. Cyclosporine inhibits the hepatic clearance of prednisone and HDL-cholesterol because of its hepatotoxic effect, which results from its interaction in the $\mathrm{P}-450$ cytochrome system ${ }^{39}$. Kobashigawa et $\mathrm{al}^{40}$ have shown that the use of pravastatin, an HMG-CoA reductase inhibitor, affects cholesterol reduction and decreases the incidence of allograft vasculopathy. Because of the beneficial evidence of treating posttransplantation dyslipidemia, the introduction of drugs from the HMG-CoA reductase inhibitor group has met the same criteria used for the general population, i.e., LDL-cholesterol levels higher 
than $130 \mathrm{mg} / \mathrm{dL}^{41}$. In our case series, we have found no relation between the levels of total cholesterol, HDL-cholesterol, and LDL-cholesterol in the groups with allograft vasculopathy and normal angiography. However, we have observed a tendency toward higher levels of triglycerides in the first group. When analyzing these results, we should consider that the patients used medication for hypercholesterolemia on a routine basis, especially HMG-CoA reductase inhibitors, which were introduced according to laboratory results to maintain total cholesterol levels lower than $200 \mathrm{mg} / \mathrm{dL}$ and LDL-cholesterol levels lower than $130 \mathrm{mg} / \mathrm{dL}$; these drugs were not suspended during the study. These drugs have an effect mainly on cholesterol; their effect on triglycerides is poor, as shown in a study by Kobashigawa et $\mathrm{al}^{42}$. This point and the greater weight gain in the group with allograft vasculopathy partially explains the results observed in the triglycerides. A further analysis, however, with a larger group of patients and with no influence from medications may help in the future to understand the real role of the lipids in the development of posttransplantation allograft vasculopathy.

In the present study, the risk factor that showed the greatest correlation with allograft vasculopathy, both in the univariate and multivariate analyses, was body mass index, which better reflected the actual nutritional status of the patient. In studies with critically ill patients in intensive care units when we considered the body mass index, we observed that malnourished and cachectic patients had a higher mortality index as compared with patients with normal body mass index ${ }^{43}$. On the other hand, high levels of body mass index also correlate with an increase in the risk of cardiovascular events ${ }^{44}$. Winters et al ${ }^{45}$ and Hauptman et al ${ }^{46}$ have found a direct relation between the elevated levels of body mass index $\left(>29 \mathrm{~kg} / \mathrm{m}^{2}\right)$ and allograft vasculopathy in patients undergoing cardiac transplantation. In our series, we have found moderate levels of body mass index compatible with grade I obesity in patients with allograft vasculopathy. Some factors seem to contribute to obesity evident in patients after cardiac transplantation. The immunosuppressive therapy, mainly corticosteroid, directly influences weight gain, as does the physical inactivity observed, despite the significant improvement in clinical findings and in functional capacity after transplantation. The nutritional conditions also improve because of a better absorption of nutrients due to reversion in heart failure and an increase in appetite, due to the use of corticosteroids. The actual role of body mass index in the context of allograft vasculopathy still awaits further clarification that goes beyond a simple assessment of the nutritional status. This index may be a marker for metabolic changes that may be occurring in patients with a greater predisposition for developing allograft vasculopathy in the late posttransplantation followup. Therefore, while these questions await clarification, some instructions should be provided to patients aiming to minimize these complications. Encouraging the practice of physical exercise, alimentary control, and attempts at withdrawal of the corticosteroid after the $6^{\text {th }}$ postoperative month may be useful measures for attaining this aim. Because allograft vasculopathy is multifactorial, the strict control of risk factors is extremely important, so that in the future with a better understanding of the actual physiopathological mechanism of this complication we will be able to interfere with its incidence and evolution, and, consequently, provide the cardiac transplantation patient with a longer survival.

\section{References}

1. Lower RR, Kontos HA, Kosek JC, Sewell DH, Graham WH. Experiences in heart transplantation. Am J Cardiol 1968; 22: 766-71.

2. Thomson JG. Production of severe atheroma in a transplanted heart. Lancet 1969; 2: 1088-92.

3. Hosenpud J, Mauck K, Hogan K. Cardiac allograft vasculopathy: IgM antibody responses to donor-specific vascular endothelium. Transplantation 1997; 63: 1602-06.

4. Fiorelli A, Stolf N, Graziosi P, et al. Incidência de coronariopatia após o transplante cardíaco ortotópico. Rev Bras Cir Cardiovasc 1994; 9: 69-80.

5. Gao SZ, Alderman EL, Schroeder JS, et al. Clinical and laboratory correlates of accelerated coronary artery disease in the cardiac transplant patient. Circulation 1987; 76: 56-61

6. Grattan MT, Moreno Cabral CE, Starnes VA, Oyer PE, Stinson EB, Shumway NE. Eight year results of cyclosporine treated patients with cardiac transplants. J Thorac Cardiovasc Surg 1990; 99: 500-09.

7. Greenberg ML, Uretsky BF, Reddy PS, et al. Long term hemodynamic follow-up of cardiac transplant patients treated with cyclosporine and prednisone. Circulation 1985; 71: 487-94.

8. Bocchi E, Vilas-Boas F, Pedrosa AA, et al. Doença coronariana após transplante cardíaco ortotópico. Arq Bras Cardiol 1994; 62: 195-200.

9. Pethig K, Besser K, Heublein B, Wahlers T, Harringer W, Haverich A. Coronary vasculopathy after heart transplantation - effect os temporal onset, severity and pro-gression on long-term prognosis. Z Kardiol 1999; 88: 498-506.

10. Lindelow B, Bergh C, Lamm C, Andersson B, Waagstein F. Graft coronary artery disease is strongly related to the aetiology of heart failure and cellular rejection. Eur Heart 1999; 20: 1326-34.
11. Halle AA, Disciascio G, Massin EK, et al. Coronary angioplasty, atherectomy and bypass surgery in cardiac transplant recipients. J Am Coll Cardiol 1995; 26 : 120-8.

12. Davies H, Al-Tikriti S. Coronary arterial pathology in the transplanted human heart. Intern J Cardiol 1989; 25: 99-118.

13. Billingham ME, Cary NRB, Hammond ME, et al. A working formulation for the standartization of nomenclature in the diagnosis of heart and lung rejection: heart rejection study group. J Heart Transplant 1990; 9: 587-601.

14. Sones FM, Shirey EK, Prondfit WL, Westcott RN. Cine-coronary arteriography. Circulation 1959; 20: 773 .

15. Uretsky BF, Murali S, Reddy S, et al. Development of coronary artery disease in cardiac transplant patients receiving immunosupressive therapy with cyclosporine and prednisone. Circulation 1987; 76: 827-34.

16. Smart FW, Ballantyne CM, Cocanougher B, et al. Insensitivity of noninvasive tests to detect coronary artery vasculopathy after heart transplant. Am J Cardiol 1991; 67: 243-7.

17. Hardesty RL, Griffith BP, Debsky RF, et al. Experience with cyclosporine in cardiac transplantation. Transplant Proc 1983; 15(suppl 1): 2553-8.

18. Hosmer DW, Lemeshow S. Applied Logistic Regression. John Wiley \& Sons, 1976: 75-118.

19. SAS Institute Inc., SAS/STATâ User's Guide. Version 6, Fourth Edition, volume 1. Cary, NC: SAS Institute Inc., 1989.

20. Radovancevic B, Poindexter S, Birovljev S, et al. Risk factors for development of accelerated coronary artery disease in cardiac transplant recipients. Eur J Cardiothorac Surg 1990; 4: 309-13. 
21. Gao SZ, Schroeder JS, Hunt SA, Valantine HA, Hill IR, Stinson EB. Influence of graft rejection on incidence of accelerated graft coronary artery disease: a new approach to analysis. J Heart Lung Transplant 1993; 12: 1029-35.

22. Costanzo-Nordin MR. Cardiac allograft vasculopathy: relationship with acute cellular rejection and histocompatibility. J Heart Lung Transplant 1992; 11: 90103.

23. Rose EA, Pepino P, Barr ML, Smith CR, Ratner AJ HO E, Berger C. Relation of HLA antibodies and graft atherosclerosis in human cardiac allograft recipients. J Heart Lung Transplant 1992; 11: 120-3.

24. Thompson ME, Shapiro AP, Johnsen AM, et al. The contrasting effects of cyclosporin A and azathioprine on arterial blood pressure and renal function following cardiac transplantation. Int J Cardiol 1986; 11: 219-29.

25. Olivari MT, Antolick A, Ring WS. Arterial hypertension in heart transplant recipients treated with three-drug immunosupressive therapy. J Heart Transplant 1989; 8: 34-9.

26. Hosenpud JD. Coronary artery heart transplantation and its relation to cytomegalovirus. Am Heart J 1999; 138 (5 Pt 2): 469-72.

27. Melnick JL, Adam E, Debakey ME. Cytomegalovirus and atherosclerosis. Eur Heart J 1993; 14: 30-8

28. Camargo LF. A importância da sorologia, antigenemia e reação em cadeia por polimerase no diagnóstico da infecção pelo citomegalovírus após-transplante cardíaco. Tese de Doutorado) - Faculdade de Medicina da Universidade de São Paulo. São Paulo, 1998: 163p.

29. Smiley ML, Mar EC, Huang ES. Cytomegalovirus infection and viral-induced transformation of human endothelial cells. J Med Virol 1988; 25: 213-26.

30. Grattan MT, Moreno-Cabral CE, Starnes VA, Oyer P, Stinson EB, Shumway NE Cytomegalovirus infection is associated with cardiac allograft rejection and atherosclerosis. J Am Med Assn 1989; 261: 3561-6.

31. Wu TC, Hruban RH, Ambinder RF, et al. Demonstration of cytomegalovirus nucleic acids in the coronary arteries of transplanted hearts. Am J Pathol 1992; 140 739-47.

32. Merigan TC, Renlund DC, Keay S, et al. A controlled trial of ganciclovir to prevent cytomegalovirus disease after heart transplantation. N Engl J Med 1992; 326: 1182-6.
33. Keogh A, Simons L, Spratt P, et al. Hyperlipidemia after heart transplantation. J Heart Transplant 1988; $7:$ 171-5.

34. Becker DM, Chamberlain B, Swank R, et al. Relationship between corticosteroid exposure and plasma lipid levels in heart transplant recipients. Am J Med 1988; 85: 632-8.

35. Chang G, Denofrio D, Desai S, et al. Lipoprotein(a) levels and heart transplantation atherosclerosis. Am Heart Journal 1998; 136(suppl 2): 329-34.

36. Maranhão R, Santos RD, Furlaneto C, et al. Lipoproteína (a), apolipoproteínas e perfil lipídico em fase tardia após-transplante cardíaco Arq Bras Cardiol 1994; 63: 465-8.

37. Bellotti G, Bocchi E, Goiato MAC, et al. Alterações do perfil lipídico na evolução tardia após transplante cardíaco. Arq Bras Cardiol 1996; 66: 263-6.

38. Renlund DG, Bristow MR, Crandall BG, et al. Hypercholesterolemia after heart tranplantation: Amelioration by corticosteroid-free maintenance imunossupression. J Heart Transplant 1989; 8: 214-20.

39. Ballantyne CM, Podet EJ, Patsch WP, et al. Effects of cyclosporine therapy on plasma lipoprotein levels. JAMA 1989; 262: 53-6.

40. Kobashigawa JA, Katznelson S, Laks H, et al. Effect of pravastatin on outcomes after cardiac transplantation. N Engl J Med 1995; 333: 621-7.

41. II Consenso Brasileiro sobre Dislipidemias. Arq Bras Cardiol 1996; 67: 1-16.

42. Kobashigawa JA, Murphy FL, Stevenson WL, et al. Low-dose lovastatin safely lowers cholesterol after cardiac transplantation. Circulation 1990; 82: 281-3.

43. Galanos AN, Pieper CF, Kussin PS, et al. Relationship of body mass index to subsequent mortality among seriously ill hospitalized patients. Crit Care Med 1997; 25: 1962-75.

44. Hubert HB, Feinleib M, McNamara PM, Castelli WP. Obesity as na independent risk factor for cardiovascular disease: a 26 year follow-up of participants in the Framingham Heart Study. Circulation 1983; 67: 968-77.

45. Winters GL, Kendall TJ, Stanley J, et al. Posttransplant obesity and hyperlipidemia: Major predictors of severity of coronary arteriopathy in failed human heart allografts. J Heart Transplant 1990; 9: 364-71.

46. Hauptman P, Davis S, Miller L, Yeung A. The role of nonimmune risk factors in the development and progression of graft atherosclerosis: preliminary insights from a Multicenter Intravascular Ultrasound Study. J Heart Lung Transplant 1995; $14: 238-42$ 